\title{
Refining Control of Top- and Bottom-blowing Converter \\ by Manipulating Bottom-blown Gas Flow Rate*
}

\author{
By Hei-ichiro ISO,** Yujiro UEDA,*** Toru YOSHIDA,*** \\ Shouichi OSADA,**** Shujiro ETO**** and Keiji ARIMA ${ }^{* * *}$
}

\begin{abstract}
Synopsis
The effect of gas bottom-blowing condition on the refining characteristics of a top-and bottom-blowing converter in comparison with that of topblowing condition has been studied, on the basis of the amount of accumulated oxygen in the converter (Os), which represents the change in oxidation/reduction reactions between hot metal and slag.

It is possible to express quantitatively the relationships between hard blow/soft blow by the manipulation of top-blowing jets and strong agitation/weak agitation by that of bottom-blown gas. The manipulation of the flow rate of bottom-blown gas permits to control the blowing reaction more effectively than that of the top-blowing jet.

In connection with the above fact, dynamic control of blowing reaction in the top-and bottom-blowing converter has been done, with the flow rate of bottom-blown gas as a manipulated variable and the variation of Os as a controlled variable. By the application of the multistep optimum control theory to the blowing reaction model, the stability of blowing operation and metallurgical characteristics, i.e., the ranges of changes in (T.Fe) of slag, phosphorus and manganese concentration of molten steel at blow end, were narrowed appreciably.
\end{abstract}

Key words: oxygen converter; top- and bottom-blowing converter; refining reaction; agitation energy; bottom blowing ; computor control; dynamic control.

\section{Introduction}

Recent advances in oxygen bottom-blowing converter processes (Q-BOP etc.) revealed insufficiency of bath agitation in the conventional top-blowing converter. This led to the development of a top- and bottom-blowing converter process which aims at increasing bath agitation by bottom-blown gas as well as top-blown gas.

In order to determine the agitation characteristic of the bottom-blown gas in bottom-blowing or topand bottom-blowing converter, the physical mixing condition of liquid has been studied by the use of such chemical engineering parameters as agitation energy and time required for uniform mixing based mainly on the water model experiment. ${ }^{1-3)}$ From the results obtained, the required ratio between top-blown gas and bottom-blown gas has been determined. However, in the case of the top- and bottom-blowing converter developed in an early stage, the flow rate of bottom-blown gas could hardly be changed, and dephosphorization was inferior to that of top-blowing converters. ${ }^{4}$ ) From this reason, top- and bottomblowing was applied almost exclusively to converters producing low carbon steels. Then, a new type of top- and bottom-blowing converter of which the flow rate of bottom-blown gas could widely be changed was developed. ${ }^{5,6)}$ As a results, it has become possible to produce a wide variety of steel from low carbon steel to high carbon steel by the top- and bottomblowing converter.

Incidentally, from the experience in actual operations of top- and bottom-blowing converters, it has revealed that in order to obtain the economic effects, i.e., improvement of steel yield by a reduction of iron content in slag (hereafter called (T.Fe)) and a reduction of ferroalloy consumption by an increase in manganese content of hot metal, it is not always necessary to maintain such a flow rate of bottom-blown gas that the former researchers considered to be necessary.

Therefore, such a new model that the dynamic effects of bottom-blown gas on the reactions can be evaluated accurately should be established.

In the light of blowing control technology, too, neither a blowing control model which is able to express the characteristics of a top- and bottom-blowing converter accurately nor an effective method which is able to controll blowing operation of a top- and bottom-blowing converter had been reported, though various blowing control methods had been developed for top-blowing converters. As the blowing control models for top- and bottom-blowing converters, there are only a few examples adapted the static blowing control model which simply corrects the change in blowing condition of bottom-blown gas or the dynamic blowing control model originally developed for top-blowing converters. ${ }^{7)}$ Thus, any appreciable results obtained by the use of the model which is able to make a dynamical estimation, for example, the effect of the change in flow rate of bottom-blown gas on the refining reactions have not been reported. In this respect, a model which is able to evaluate quantitatively the dynamic effects of bottom-blown gas is also required.

In order to explain the refining characteristics of bottom-blowing gas in a top- and bottom-blowing converter, the authors utilized the information of exhaust gas to calculate the amount of oxygen accumulated in the converter (hereafter called (Os)) which represents the changes in conditions of oxidation and reduction between hot metal and slag in the converter.

\footnotetext{
* $\quad$ Manuscript received on August 3, 1987; accepted in the final form on December 11, 1987. C 1988 ISIJ

** Formerly Sakai Works, Nippon Steel Corporation. Now at R \& D Laboratories-III, Nippon Steel Corporation, Edamitsu, Yahatahigashi-ku, Kitakyushu 805.

*** Sakai Works, Nippon Steel Corporation, Chikko-Yawata-cho, Sakai 590.

**** New Materials Project Bureau, Nippon Steel Corporation, Otemachi, Chiyoda-ku, Tokyo 100.

***** Electronics \& Information Systems Division, Nippon Steel Corporation, Otemachi, Chiyoda-ku, Tokyo 100.
} 
This paper describes the characteristics of hot metal agitation by bottom-blown gas in a top- and bottomblowing converter analyzed by $\mathrm{Os}$ as a dynamic parameter of the reactions between hot metal and slag, and the method of dynamic control of the blowing reactions in top- and bottom-blowing converter with Os as a means of evaluation, and with bottom-blown gas as a means of dynamic control.

\section{Experimental Method}

\section{Top- and Bottom-blowing Converter}

The experiments were done with a 170-t top- and bottom-blowing converter at Sakai Works (hereafter called $\left.\mathrm{LD}-\mathrm{CB}^{5)}\right)$. This converter uses $\mathrm{CO}_{2}, \mathrm{~N}_{2}$, or $\mathrm{Ar}$ as bottom-blown gas as shown in Fig. 1. A maximum gas pressure is $25 \mathrm{~kg} / \mathrm{cm}^{2}$. Figure 2 shows the design of the bottom-blowing nozzle. The nozzle made of refractory has multiple small-diameter pipes with a common header. The most remarkable feature of this nozzle is that the flow rate of bottomblown gas can widely be changed freely in a short time during blowing.

\section{Amount of Oxygen Accumulated in Converter Calculated from Information of Exhaust Gas}

Figure 3 shows the system to calculate the amount of oxygen accumulated in the converter on the basis of the information of exhaust gas. The dynamic control system originally used for top-blowing convert- ers ${ }^{8)}$ has been modified so as to calculate Os, which is a dynamic parameter of refining reactions in the top- and bottom-blowing converter. Actually, Os is calculated as follows. First, the change in oxygen balance of the converter is calculated from Eq. (1). Then, it is integrated, and the amount of oxygen which reacts with silicon in the hot metal to form silicon dioxide, and is not directly given any effects on the subsequent oxidation and reduction in the converter as in Eq. (2), is subtracted from it.

$$
\begin{aligned}
& d \mathrm{Os}=\left\{F_{T \mathrm{O}_{2}}+F_{B \mathrm{CO}_{2}}+\sum_{i}\left(\alpha_{i}+\beta_{i}+1 / 2 \gamma_{i}\right) W_{i}\right\} \\
& -\left(1 / 2 F_{\mathrm{CO}}^{E}+F_{\mathrm{CO}_{2}}^{E}\right) \\
& \mathrm{Os}=\int_{t}(d \mathrm{Os}) d t-\kappa W_{\mathrm{HM}}[\mathrm{Si}]_{\mathrm{HM}}
\end{aligned}
$$

here, $\quad F_{\mathrm{CO}}^{E}=F_{\mathrm{CO}}+2 \cdot\left(21 / 79 F_{\mathrm{N}_{2}}-F_{\mathrm{O}_{2}}\right)$

$F_{\mathrm{CO}_{2}}^{E}=F_{\mathrm{CO}_{2}}-2 \cdot\left(21 / 79 F_{\mathrm{N}_{2}}-F_{\mathrm{O}_{2}}\right)$

$F_{\mathrm{CO}}=F_{e x}(t-\tau) C_{\mathrm{CO}}(t)$

$F_{\mathrm{CO}_{2}}=F_{e x}(t-\tau) C_{\mathrm{CO}_{2}}(t)$

$F_{\mathrm{N}_{2}}=F_{e x}(t-\tau) C_{\mathrm{N}_{2}}(t)$

$F_{\mathrm{O}_{2}}=F_{e x}(t-\tau) C_{\mathrm{O}_{2}}(t)$

where, $d \mathrm{Os}$ : Change in oxygen balance of converter $\left(\mathrm{Nm}^{3} / \mathrm{h}\right)$

Os: Amount of oxygen accumulated in converter $\left(\mathrm{Nm}^{3}\right)$

$F_{T \mathrm{O}_{2}}$ : Flow rate of top-blown oxygen $\left(\mathrm{Nm}^{3} /\right.$ h)

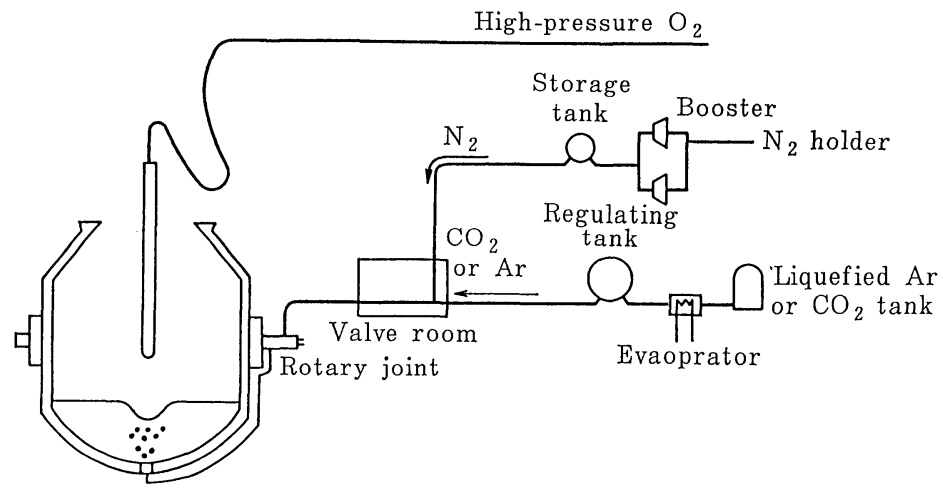

Fig. 1. Outline of top- and bottom-blowing converter (LD-CB).

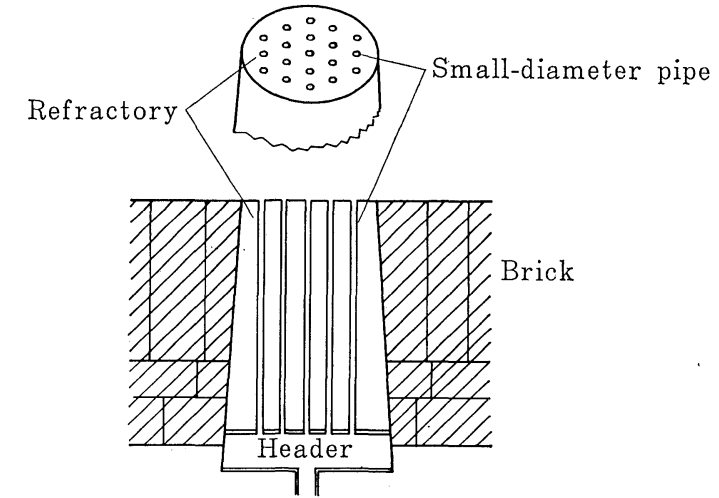

Fig. 2. Design of bottom-blowing nozzle.
Fig. 3. Measuring system of top- and bottomblowing converter.

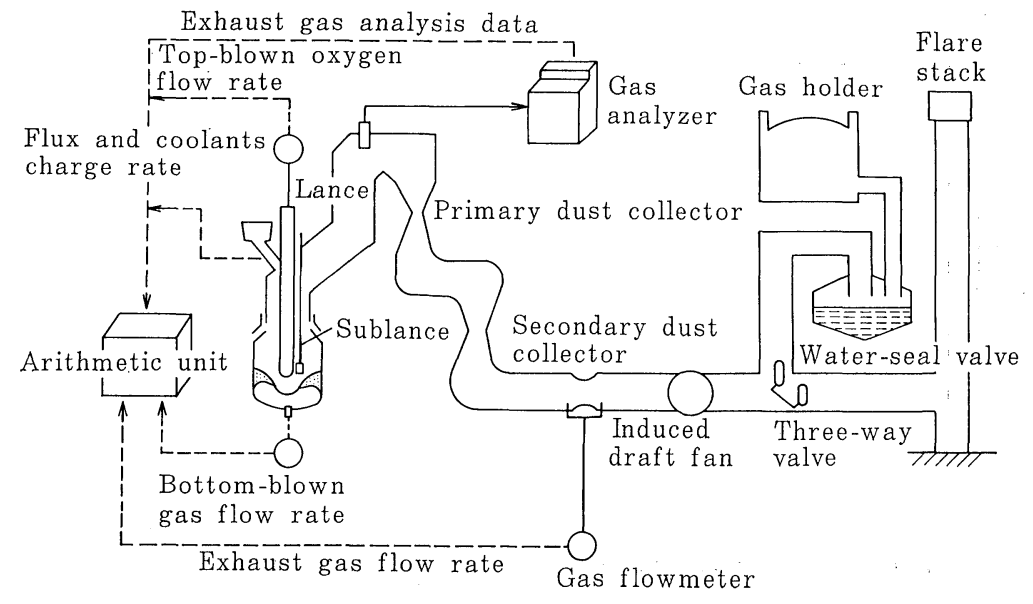


$F_{B \mathrm{CO}_{2}}$ : Flow rate of bottom-blown carbon dioxide $\left(\mathrm{Nm}^{3} / \mathrm{h}\right)$

$\alpha_{i}$ : Oxygen contained in flux and coolant of $i$ except for oxygen combined with carbon $\left(\mathrm{Nm}^{3} / \mathrm{kg}\right)$

$\beta_{i}$ : Garbon dioxide contained in flux and coolant of $i\left(\mathrm{Nm}^{3} / \mathrm{kg}\right)$

$\gamma_{i}$ : Hydrogen contained in flux and coolant of $i\left(\mathrm{Nm}^{3} / \mathrm{kg}\right)$

$W_{i}$ : Charged ratio of flux and coolant of $i$ $(\mathrm{kg} / \mathrm{h})$

$i$ : Type of flux and coolant

$F_{\mathrm{CO}}$ : Flow rate of carbon monoxide in exhaust gas $\left(\mathrm{Nm}^{3} / \mathrm{h}\right)$

$F_{\mathrm{CO}_{2}}$ : Flow rate of carbon dioxide in exhaust gas $\left(\mathrm{Nm}^{3} / \mathrm{h}\right)$

$F_{\mathrm{N}_{2}}$ : Flow rate of nitrogen in exhaust gas $\left(\mathrm{Nm}^{3} / \mathrm{h}\right)$

$F_{\mathrm{O}_{2}}$ : Flow rate of oxygen in exhaust gas $\left(\mathrm{Nm}^{3} / \mathrm{h}\right)$

$F_{\text {co }}^{E}$ : Flow rate of carbon monoxide generated in converter $\left(\mathrm{Nm}^{3} / \mathrm{h}\right)$

$F_{\mathrm{CO}_{2}}^{E}$ : Flow rate of carbon dioxide generated in converter $\left(\mathrm{Nm}^{3} / \mathrm{h}\right)$

$F_{e x}:$ Flow rate of exhaust gas $\left(\mathrm{Nm}^{3} / \mathrm{h}\right)$

$C_{\mathrm{CO}}$ : Concentration of carbon monoxide in exhaust gas

$C_{\mathrm{CO}_{2}}$ : Concentration of carbon dioxide in exhaust gas

$C_{\mathrm{N}_{2}}$ : Concentration of nitrogen in exhaust gas

$C_{\mathrm{O}_{2}}$ : Concentration of oxygen in exhaust gas

$t:$ Time (s)

$\tau$ : Delay time of exhaust gas analyzer (s)

$W_{\text {HM }}$ : Weight of hot metal $(\mathrm{kg})$

$[\mathrm{Si}]_{\mathrm{HM}}$ : Concentration of silicon in hot metal $(\%)$

$\kappa$ : Coefficient of conversion of silicon into silicon dioxide.

\section{Study of Blowing Reaction Behavior}

In the middle period of blowing, the flow rate of top-blown oxygen and the lance height (manipulated variables for top-blowing) and the flow rate of bottom-blown $\mathrm{CO}_{2}$ (manipulated variable for bottom blowing) were varied stepwise independently to study the changes in $d \mathrm{Os}$ caused by the variations of those manipulated variables.

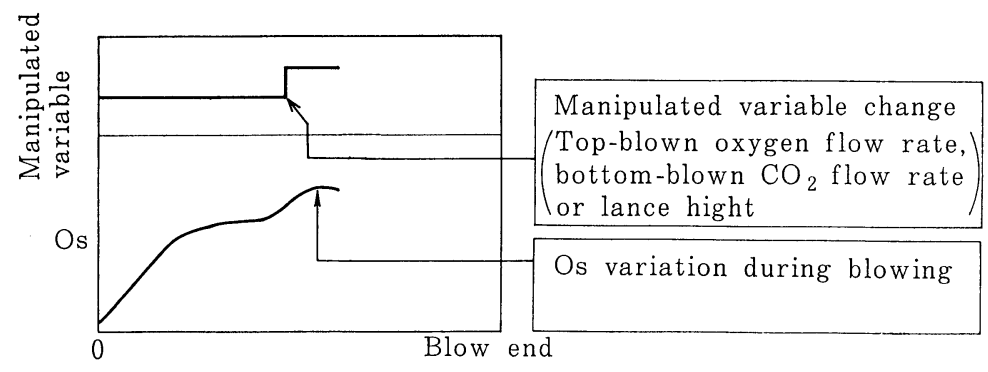

Blowing time

Fig. 4. Scheme for study of effect of manipulated variable on Os.
The experimental method is schematically shown in Fig. 4. The chemical compositions of metal and slag needed for the subsequent experiments were determined by emission spectroscopic analysis and fluorescent X-ray analysis, respectively.

\section{Results of Experiment}

Figure 5 shows the experimental results, with each of the manipulated variables on the horizontal axis and the change in $d \mathrm{Os}$ on the vertical axis. Each manipulated variable shows a good correlation with the change in $d \mathrm{Os}$ : the lance height shows a positive correlation, and the flow rates of top-blown oxygen and bottom-blown $\mathrm{CO}_{2}$ each show a negative correlation. It should be noted, however, that in actual blowing operation the variable range of lance height is limited in a certain range and that in the range adopted in the present experiment the lance height has less remarkable effect on $d \mathrm{Os}$ than that of the flow rate of top-blown oxygen or bottom-blown $\mathrm{CO}_{2}$ which can be varied more widely.

\section{Discussion}

\section{Evaluation of Effect of Bottom-blown Gas Flow Rate on $d \mathrm{Os}$}

In a top-blowing converter, so-called hard blow or soft blow has been common practice. ${ }^{9)}$ Namely, as a manipulated variable in the blowing reaction, the lance height or the flow rate of top-blown oxygen is varied to adjust the depth of cavity in the hot metal formed by the jet of top-blown oxygen, and thereby the reaction between hot metal and slag can be controlled over a wide range.

The unified formula $L / L_{0}$ which represents the depth of cavity formed by the jet of top-blown oxygen $^{10)}$ has been used as an index of field operation for
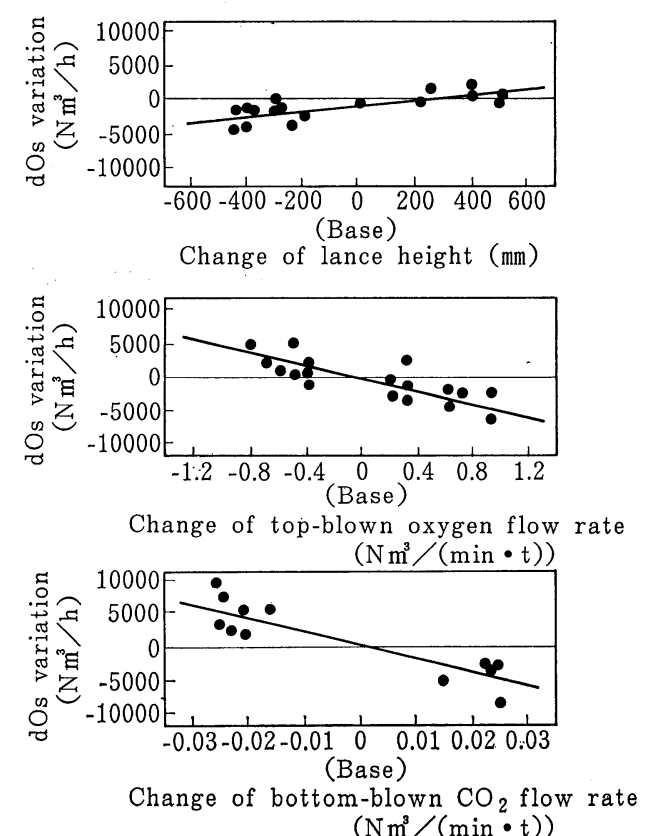

Fig. 5. Relationships between change of manipulated variable and $d \mathrm{O}$ s variation. 
some 20 years. However, in the light of blowing control, the unified formula $L / L_{0}$ is significantly influenced by some disturbance factors which are hardly represented by the model, such as the changes in converter profile due to wear of the converter brick and deterioration of the shape of nozzle at the lance tip, and hence it lacks reliability as a dynamic parameter of blowing reactions.

On the other hand, the authors already reported that Os directly indicates the change in condition of oxidation/reduction in the converter, and that by the use of Os, it is possible to estimate the slagging behavior and the change in reaction between slag and hot metal caused by the change in oxidation/reduction condition with the lapse of time. ${ }^{8)}$ In the present experiment with Os as shown in Fig. 5, attention has been paid to the fact that the flow rate of topblown oxygen, lance height, and flow rate of bottomblown $\mathrm{CO}_{2}$, which are manipulated variables of different nature, clearly and dynamically represent the operational indexes of blowing condition, that is, hard blow/soft blow by the jet of top-blown oxygen and strong agitation/weak agitation by the bottom-blown gas, as an increase or a decrease in Os of slag, or the change in condition of oxidation/reduction between slag and hot metal.

For example, it is common practice to raise the lance or to decrease the flow rate of top-blown oxygen for soft blow so as to increase the potential of slag oxidation and to enhance the reaction of dephosphorization in the converter. In this case, $d \mathrm{O}$ s increases. The same effect can be attained by reduction of flow rate of bottom-blown gas, or weak agitation, as is verified by the relationships shown in Fig. 5 .

This implies that differing from the unified formula $L / L_{0}$ which was only the index of top-blowing conditions for blowing reaction for a long time, Os can dynamically and quantitatively represent not only the top-blowing conditions but also the bottom-blowing conditions. Thus, Os is able to use as a dynamic parameter to accurately evaluate reaction control during blowing operation.

Attention should also be paid to the controlling characteristics of the flow rate of bottom-blown $\mathrm{CO}_{2}$ and the flow rate of top-blown oxygen by $d$ Os. Namely, the manipulation effect of the flow rate of bottom-blown $\mathrm{CO}_{2}$ to cause a change in $d \mathrm{Os}$ is almost several ten times as large as the manipulation effect of the flow rate of top-blown oxygen to cause the same change in $d \mathrm{Os}$.

As already mentioned, in the control of the blowing reactions, the manipulation of the top-blowing conditions significantly affects the blowing time. In particular, the manipulation of lance height causes a wide fluctuation of thermal load at the lance tip or upper furnace brick, being impaired the converter workability. Thus, the range of manipulation of top-blowing conditions is naturally limited. Besides, excessive manipulation of top-blowing conditions changes the flame point on the hot metal bath drastically, being impaired the stability of a blowing operation.

On the other hand, bottom-blowing conditions can be manipulated without the influence on blowing time or workability, leading to the stable control of blowing reaction on the basis of the agitation condition in the converter. In addition, the flow rate of bottomblown gas has much greater control gain on $d \mathrm{Os}$ than the flow rate of top-blown oxygen. Thus, the flow rate of bottom-blown gas can be regarded as a superior manipulated variable which controls the blowing reaction effectively.

\section{Evaluation of Agitation Energy in Top- and Bottom- blowing Converter}

From the observed effects of various manipulated variables on $d \mathrm{Os}$ in a top- and bottom-blowing converter, the authors studied the effects of top-blown gas and bottom-blown gas on the agitation of hot metal.

Equations for the agitation energy by top-blown gas and bottom-blown gas derived by $\mathrm{Kai}^{11)}$ were used for the evaluation of hot metal agitation, and are given in Eqs. (3) and (4). To calculate the total agitation energy, Eq. (5) is given.

$$
\begin{aligned}
& \dot{\varepsilon}_{V B}=\frac{6.18 F_{B} T_{L}}{V_{L}} \cdot\left\{2.3 \log \frac{P_{a}+\rho B}{P_{a}}+\eta\left(1-\frac{T_{n}}{T_{L}}\right)\right\} \\
& \dot{\varepsilon}_{V T}=\frac{0.632 \cdot 10^{-6} \cos \xi}{V_{L}} \cdot \frac{F_{T}^{3} m}{n^{2} d^{3} h} \\
& \dot{\varepsilon}_{T}=\dot{\varepsilon}_{V B}+\lambda \dot{\varepsilon}_{V T}
\end{aligned}
$$

where, $\dot{\varepsilon}_{V B}$ : Agitation energy by bottom-blown gas $\left(\mathrm{W} / \mathrm{m}^{3}\right)$

$\dot{\varepsilon}_{V T}$ : Agitation energy by top-blown gas (W/ $\mathrm{m}^{3}$ )

$\dot{\varepsilon}_{\mathrm{T}}:$ Total agitation energy $\left(\mathrm{W} / \mathrm{m}^{3}\right)$

$T_{L}$ : Temperature of bath $(\mathrm{K})$

$T_{n}$ : Temperature of gas before bottom-blowing $(\mathrm{K})$

$\mathrm{V}_{L}:$ Volume of bath $\left(\mathrm{m}^{3}\right)$

$P_{a}: \quad$ Pressure on bath surface $\left(\mathrm{kg} / \mathrm{m}^{2}\right)$

$\rho:$ Density of bath $\left(\mathrm{kg} / \mathrm{m}^{3}\right)$

$B$ : Depth of bath (m)

$\lambda$ : Efficiency of agitation energy transmission of top-blown gas

$\eta$ : Efficiency of energy transmission

$F_{B}$ : Flow rate of bottom-blown gas $\left(\mathrm{Nm}^{3} /\right.$ $\min$ )

$F_{T}$ : Flow rate of top-blown gas $\left(\mathrm{Nm}^{3} / \mathrm{min}\right)$

$m$ : Mole

$n$ : Number of nozzles on a lance tip

$d$ : Diameter of nozzle outlet (m)

$h$ : Gap between lance tip and bath level (m)

$\xi$ : Angle of lance nozzle (deg).

In Eq. (5), the efficiency of agitation energy transmission by top-blown gas (hereafter called $\lambda$ ) was introduced by $\mathrm{Kai}$ in his water model experiment to measure the change in electric conductivity with the lapse of time by the addition of $\mathrm{KCl}$. In comparison with the effect of agitation energy on the time required for uniform mixing under top- and bottomblowing conditions, he assumed that the coefficient of utilization of top-blowing energy for mixing by agita- 
tion is about one tenth as small as that of bottomblowing energy.

Kai estimated that the kinetic energy of top-blown jet is partly consumed in the occurrence of violent splash. Thus, he considered that the force of hot metal agitation depends mainly on the flow rate of bottom-blown gas.

On the other hand, in the experiment done by the authors in Fig. 5 on the effects of various manipulated variables on the change in condition of oxidation/ reduction reactions between hot metal and slag in the converter, the manipulation of top-blowing conditions, as well as the manipulation of bottom-blowing conditions, shows an appreciable effect.

In connection with the above-mentioned experiment, the authors calculated the total agitation energy in each of the cases where the individual manipulated variables were varied so as to show the same $d$ Os with Eqs. (3) to (5). The reference values shown in Table 1, being obtained from Fig. 5 were used in calculations. Figure $6(\mathrm{a})$ shows the calculation results. In this figure, the horizontal axis labeled the change in individual manipulated variable giving the same $d \mathrm{Os}$, the total agitation energy was taken as abscissa, and $\lambda$ was taken as $1 / 10$.

Of the three manipulated variables, only the flow rate of bottom-blown gas has significant effect on the

Table 1. Comparison of changes of various manipulated variable.

\begin{tabular}{|c|c|c|c|}
\hline \multirow{2}{*}{$\begin{array}{l}\text { Change of manipulated variable } \\
\text { giving equivalent } d \text { Os variation }\end{array}$} & \multicolumn{3}{|c|}{$\begin{array}{c}\text { Equivalent } d \mathrm{Os} \\
\text { variation }\left(\mathrm{Nm}^{3} / \mathrm{h}\right)\end{array}$} \\
\hline & -2500 & 0 & 2500 \\
\hline Lance height $(\mathrm{mm})$ & -200 & 0 & 200 \\
\hline $\begin{array}{l}\text { Top-blown oxygen flow rate } \\
\left(\mathrm{Nm}^{3} /(\min \cdot \mathrm{t})\right)\end{array}$ & 0.2 & 0 & -0.2 \\
\hline $\begin{array}{l}\text { Bottom-blown } \mathrm{CO}_{2} \text { flow rate } \\
\left(\mathrm{Nm}^{3} /(\min \cdot \mathrm{t})\right)\end{array}$ & 0.01 & 0 & -0.01 \\
\hline
\end{tabular}

total agitation energy and the effect of top-blown jet is almost negligibly small. This relationship is greatly different from the close correlations between the manipulated variables and $d$ Os shown in Fig. 5 .

Figure $6(\mathrm{~b})$ shows the total agitation energy calculated on the assumption that $\lambda$ is unity instead of 0.1 .

In Fig. 6(b), it is noteworthy that the total agitation energy is calculated on the assumption of the same transmission efficiency for both the agitation energy by top-blown gas and the agitation energy by bottom-blown gas. This means that the relationships between the individual manipulated variables and $d \mathrm{Os}$ or the total agitation energy can be expressed on a similar basis, and also verifies the validity of dynamic parameter $d$ Os.

Thus, by the introduction of the concept of $d \mathrm{Os}$, it has become possible not only to determine quantitatively the mutual relationship between manipulated variables of different nature such as the flow rate of top-blown oxygen, lance height and flow rate of bottom-blown gas, but also to express in a unified manner the mutual relationship between agitation energies with manipulated variables calculated by chemical engineering means. In the former studies of the effects of bottom-blowing conditions on the improvement of refining reactions compared with those of topblowing conditions, the agitation energy and time required for uniform mixing expressed under physical mixing condition in a simple system on basis of a water model were used as parameters, and hence the model lacked consistency in that, for example, the effect of top-blown jet was corrected in comparison with that of the bottom-blown gas on the assumption of a loss of energy on the surface of cavity. In the present study, the dynamic parameter Os which expresses the changes in chemical reactions (oxidation/ reduction) between hot metal and slag was used for the base model, being able to express the contribu-

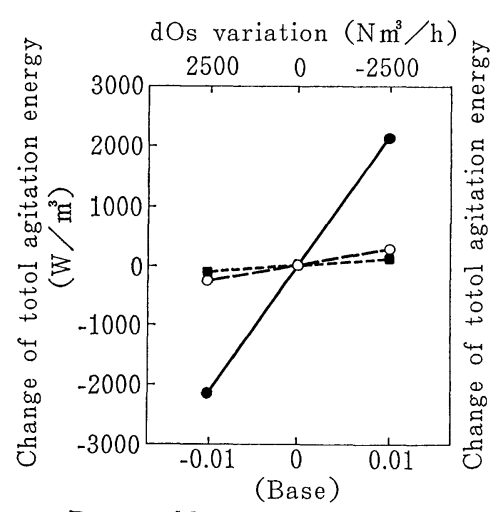

Bottom-blown $\mathrm{CO}_{2}$ flow rate

$\left(\mathrm{Nm}^{3} /(\min \cdot \mathrm{t})\right)$

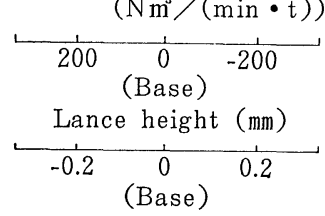

Top-blown oxygen flow rate $\left(\mathrm{Nm}^{3} /(\mathrm{min} \cdot \mathrm{t})\right)$

(a) $\lambda=0.1$

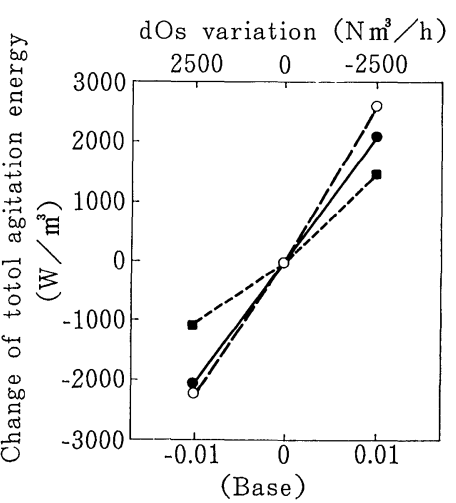

Bottom-blown $\mathrm{CO}_{2}$ flow rate $\left(\mathrm{Nm}^{3} /(\min \cdot t)\right)$

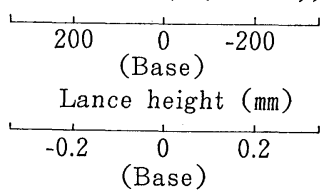

Top-blown oxygen flow rate $\left(\mathrm{Nm}^{3} /(\min \cdot \mathrm{t})\right)$

(b) $\lambda=1.0$

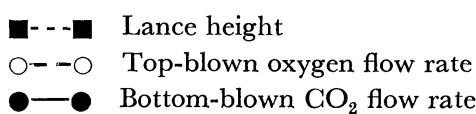

Fig. 6.

Relationships between change of various manipulated variables giving equivalent $d \mathrm{Os}$ variation and change of total agitation energy. 
tions of top-blowing and bottom-blowing conditions for the improvement of refining reactions in a more consistent manner.

In order to evaluate the effect of bottom-blown gas in a top- and bottom-blowing converter in the future, it is considered to be effective to analyze the changes in chemical reactions between hot metal and slag which take place in an actual converter, as well as the experimental results obtained by a water model.

In the methods of dynamic control of a top- and bottom-blowing converter, the authors considered that it is necessary to use such a new model as a dynamic parameter, for example, Os which expresses the changes in chemical reactions of the converter.

The application of a dynamic blowing control model to a top- and bottom-blowing converter is discussed below.

\section{Application of Optimum Blowing Reaction Control Model to Actual Process}

\section{Blowing Reaction Control Model}

On the whole, the blowing reaction taking place in a converter is considered to be in a quasiequilibrium state. However, it is known that the variance of blow-end state is generally wider than that expected from the equilibrium theory. The authors stated that wider variance is partly due to a variation of the process of blowing reaction.

Figure 7 schematically shows the behavior of blowing reaction as the change in Os. The change in Os shown here is relative to the cumulative amount of oxygen rather than the blowing time. This is because in actual operation, the rate of top-blown oxygen used for blowing is a more direct operational indicator than the blowing time. In Fig. 7, Os patterns (I) and (II) show the same Os value at the blow end, but they differ in metallurgical characteristics during blowing and at the blow end. This is considered to be due to differences in the slagging behavior of lime, the reactions of slag (especially, dephosphorization and demanganization), etc. Since dynamic blowing control

\begin{tabular}{|c|c|}
\hline Os & Blowing characteristic at blow end \\
\hline (I) & $\begin{array}{l}\text { Good dephosphorization, } \\
\text { high manganese concentration }\end{array}$ \\
\hline (II) & $\begin{array}{l}\text { Poor dephosphorization, } \\
\text { low manganese concentration }\end{array}$ \\
\hline
\end{tabular}

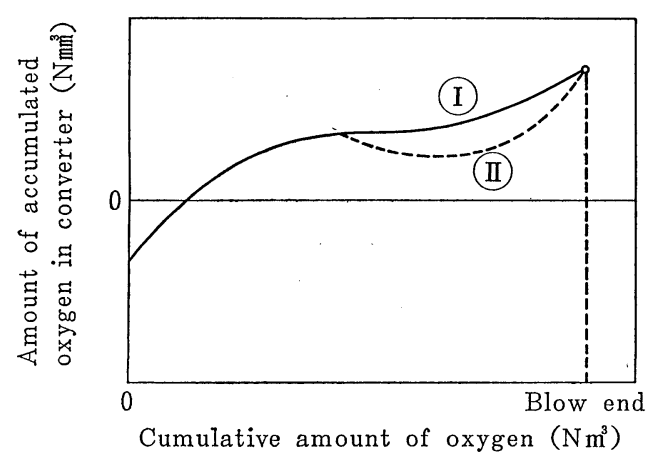

Fig. 7. Changes of Os during blowing and their blowing characteristic. with emphasis placed only on the blow-end value of Os was considered to have insufficient accuracy, the authors decided to use a model by which the process of Os variation can be more accurately controlled.

As already mentioned, in a top- and bottom-blowing converter, the flow rate of bottom-blown gas has a much greater control gain on the blowing reactions than the top-blown gas jet, and the condition of blowing reaction can be controlled without causing significant effect on the blowing time, blowing operation, etc., by minimizing the manipulation of top-blown gas jet. Taking these into consideration, the authors decided to use the flow rate of bottom-blown gas as a dynamic controlled variable in the model. Namely, the top-blown gas jet was excluded from dynamic control variables. Instead, it was treated as an object of program control. Since Os represents the result of integration of oxidation/reduction processes, it is considered that Os is described by the liner equation given in Eq. (6):

$$
y_{p}(k)=a y_{p}(k-1)+b u(k-1)
$$

where, $y_{p}$ : Os value as the process output

$u$ : Variation of flow rate of bottom-blown gas as the process input

$k$ : Sampling time

$a, b:$ Parameters.

Also, in light of Os behavior shown in Fig. 7, it is expected that the mechanism of oxidation/reduction during blowing will vary according to the period of blowing. Therefore, the authors considered that the characteristics of blowing reaction can well be expressed by treating as a time-dependent system which is difficult to express the entire section of blowing by the same parameters $a, b$ in Eq. (6).

So, in consideration of the variations of oxidation/ reduction in the initial, middle, and final stages of the blowing period shown in Fig. 8, the middle stage which is longer than the other two stages was subdivided. Therefore, the entire blowing period was divided into 5 stages, in each of which a deviation from the mean value of aimed Os was used.

\section{Optimum Control Model}

For the blowing reaction model defined by Eq. (6), the optimum control theory was applied to determine

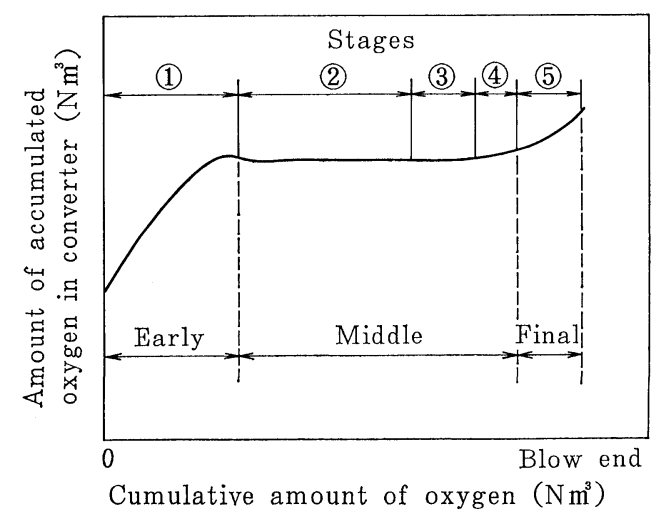

Fig. 8. Example of division of blowing period into stages. 
the flow rate of bottom-blown gas as a manipulated variable. In this case, it is necessary to identify the parameters, $a$ and $b$. The identification on the basis of MRAS (Model Reference Adaptive System)12,13) was adopted.

The reference model is discribed by Eq. (7).

$$
y_{p}(k)=P^{\mathrm{T}}(k-1) \phi(k-1)
$$

here, $P^{\mathrm{T}}(k-1)=[f(k-1) g(k-1)]$

$\phi^{\mathrm{T}}(k-1)=\left[y_{p}(k-1) u(k-1)\right]$

$P$ : Parameter vector

$\phi:$ Estimation model vector

$f(k)$ : Parameter $a$ at $k$ point

$g(k)$ : Parameter $b$ at $k$ point.

The equation for identification is shown below, with MRAS theorem 3.2. ${ }^{14)}$

$$
P(k)=P(k-1)+\frac{F(k-1) \phi(k-1)}{1+\phi^{\mathrm{T}}(k-1) F(k-1) \phi(k-1)} \cdot v(k)
$$

here, $F:$ Adaptive gain

$v$ : Identification error signal.

In terms of adaptive gain, it is assumed that $F=\operatorname{diag}$ $\left[\begin{array}{ll}1.0 & 1.0\end{array}\right]$.

An example of parameter identification is shown in Fig. 9. This example shows the identification of parameter $a$ (i.e., $f(k))$ in stage (2). Figure 9 shows that the parameter converges satisfactorily.

In terms of control algorithm, the flow rate of bottom-blown gas is subject to upper and lower limits: the lower limit is the minimum flow rate required to keep the nozzle in operation, and the upper limit is the maximum flow rate determined by installed capacity. In consideration of these limits, an aimed value was set for each stage and a multistep optimum control technique was adopted to ensure that the aimed value was reached in that stage. Namely, consider the problem of dynamic programing to minimize the evaluation function expressed by the following equation in $\mathcal{N}$ steps.

$$
J_{N}=\sum_{j=1}\left[Q(j) y_{p}^{2}(j)+H(j-1) u^{2}(j-1)\right] \ldots
$$

here, $J_{N}$ : Performance index

Q. $H$ : Weight functions.

By the application of the principle of optimality (" assuming that optimum control is at work, optimality must be maintained in any section from an arbitrary point to the end point "), ${ }^{15,16)}$ the following equation can be obtained.

$$
\begin{aligned}
\min J_{N-k}= & \min \left\{Q(k+1) y_{p}^{2}(k+1)+H(k) u^{2}(k)\right. \\
& \left.+\min J_{N-(k+1)}\right\} \quad \ldots \ldots \ldots \ldots \ldots \ldots \ldots \ldots \ldots \ldots \ldots
\end{aligned}
$$

From Eq. (10), the optimum manipulated variable $u(k)$ can be obtained by the following equation.

$$
\partial J_{N-k} / \partial u(k)=0
$$

From Eqs. (10) and (11), the optimum manipulated variable is expressed as follows.

$$
u(k)=T(\mathcal{N}-k) y_{p}(k)
$$

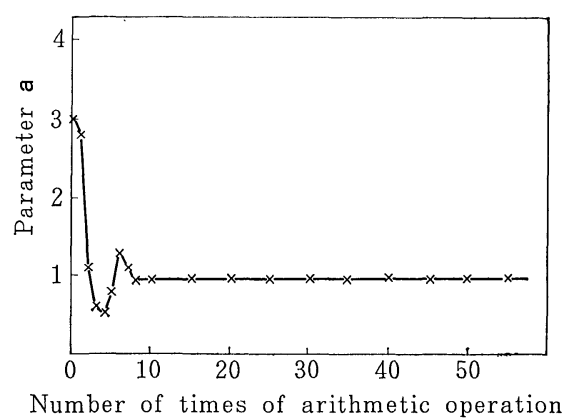

Fig. 9. Example of change of parameter $a$.

$$
\text { here, } \begin{aligned}
\mathcal{T}(\mathcal{N}-k)= & -\left[S_{g g}(\mathcal{N}-(k+1))+H(k)\right]^{-1} \\
& \cdot S_{g f}(\mathcal{N}-(k+1)) \\
S_{g g}(\mathcal{N}-(k+1))= & g^{2}(k)[Q(k+1)+R(\mathcal{N}-(k+1))] \\
S_{g f}(\mathcal{N}-(k+1))= & g(k) f(k)[Q(k+1)+R(\mathcal{N}-(k+1))] \\
= & S_{f g}(\mathcal{N}-(k+1)) \\
S_{f f}(\mathcal{N}-(k+1))= & f^{2}(k)[Q(k+1)+R(\mathcal{N}-(k+1))] \\
R(\mathcal{N}-k)= & S_{f f}(\mathcal{N}-(k+1))+S_{f g}((\mathcal{N}-(k+1)) \\
& \cdot T(\mathcal{N}-k) \\
R(0)= & 0 \\
R, S, T: & \text { Variable functions. }
\end{aligned}
$$

\section{Results of Optimum Control and Considerations}

In the application of optimum control to the operation of the 170-t top- and bottom-blowing converter (LD-CB), the authors adopted $d \mathrm{Os}$ - the change in oxygen balance of converter-corresponding to the rate of oxidation/reduction in the converter as the evaluation function instead of Os to express the characteristic of dynamic blowing reaction, with the flow rate of bottom-blown $\mathrm{CO}_{2}$ as the manipulated variable.

The whole blowing period was divided into 5 stages, for each of which an aimed $d \mathrm{O}$ s was set. In setting the aimed values, the aimed optimum change in Os was selected on the basis of actual changes in Os during the past blowing operations in which the metallurgical characteristics were evaluated. Also, the mean integral value of $d \mathrm{Os}$ in each stage, or the mean gradient of Os in each stage, was calculated previously, and each stage was controlled in multiple steps so that the controlled variable $d \mathrm{Os}$ followed to the aimed value.

The weight functions, $Q$ and $H$, in Eq. (9) were determined by trial and error as follows:

$$
\begin{aligned}
& Q(j)=1 \\
& H(j-1)=5 .
\end{aligned}
$$

It was confirmed that exactly the same control as mentioned above can be done even when Os is substituted for $d \mathrm{Os}$ as the controlled variable. However, in the following explanation of an example of the application of optimum control to blowing operation, $d \mathrm{Os}$ is used as the controlled variable because (1) Os at any point of time represents a value integrated from the start of blowing, hence, theoretically, includes all errors of the exhaust gas data processing made from the start of blowing to that point of time, while $d \mathrm{Os}$ is influenced only by the error of the ex- 
haust gas data processing made at that point of time, and (2) $d$ Os has good correlation with the time-serial change in flow rate of bottom-blown $\mathrm{CO}_{2}$ as shown in Fig. 5. Controlled variable $d \mathrm{Os}$ represents the variation of Os, hence it is expressed in $\mathrm{Nm}^{3} / \mathrm{h}$. For the purpose of control, however, the unit $\mathrm{Nm}^{3}-\mathrm{Os} /$ $\mathrm{Nm}^{3}-\mathrm{O}_{2}$ obtained by dividing $d \mathrm{Os}$ by the flow rate of top-blown oxygen $\left(\mathrm{Nm}^{3} / \mathrm{h}\right)$ was used for $d \mathrm{Os}$ in the following experiments. This is because the cumulative amount of oxygen is substituted for the blowing time as an operational indicator as mentioned earlier, and hence the variation of $d \mathrm{Os}$ relative to the cumulative amount of oxygen, rather than that relative to the blowing time, should better reflect the actual condition of operation.

Figure 10 shows a scheme of $d$ Os control of an arbitrary control step of an arbitrary stage.

Figures 11 and 12, show the time-serial changes in the controlled variable without and with application of the above control.

Figure 11 shows an example of widely employed program control of the flow rate of bottom-blown gas without application of the above control. This figure shows that the controlled variable, $d \mathrm{Os}$, at the end of blowing deviates from the aimed value substantially. Figure 12 shows an example of application of the above control. The figure clearly shows that the controlled variable, $d \mathrm{Os}$, at the end of blowing slightly deviates from the target thanks to dynamic control of the flow rate of bottom-blown $\mathrm{CO}_{2}$, which is the manipulated variable.

Figure 13 shows the standard deviation of difference between the actual and aimed values of $d \mathrm{Os}$ for each stage. The figure shows that as the control proceeds from one stage to another, the standard devia-

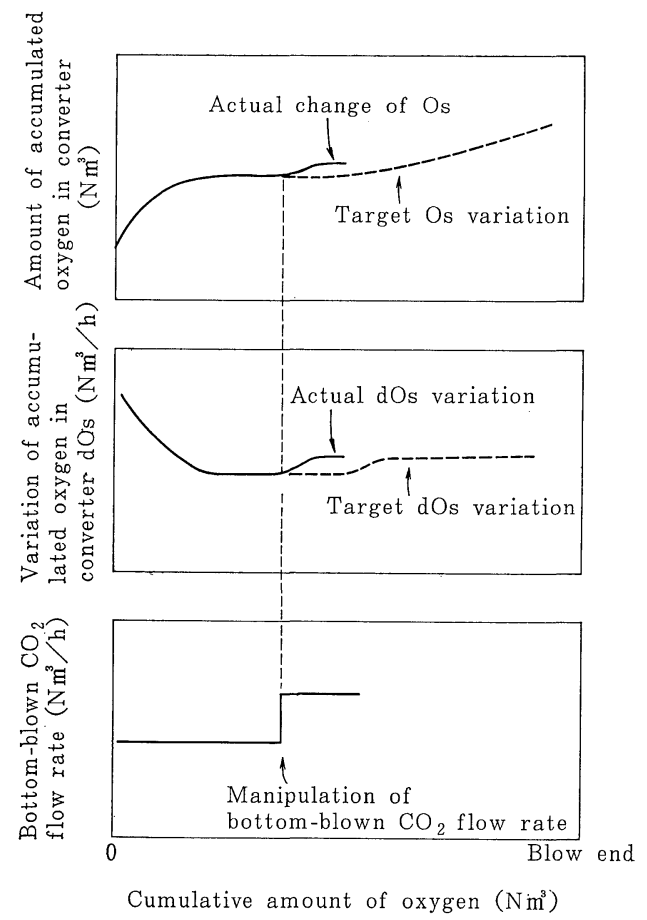

Fig. 10. Image of dynamic optimum control of top- and bottom-blowing converter. tion of the controlled variable in the blowing operation without the above control increases gradually, while that in the blowing operation with the above control decreases appreciably. All this suggests the
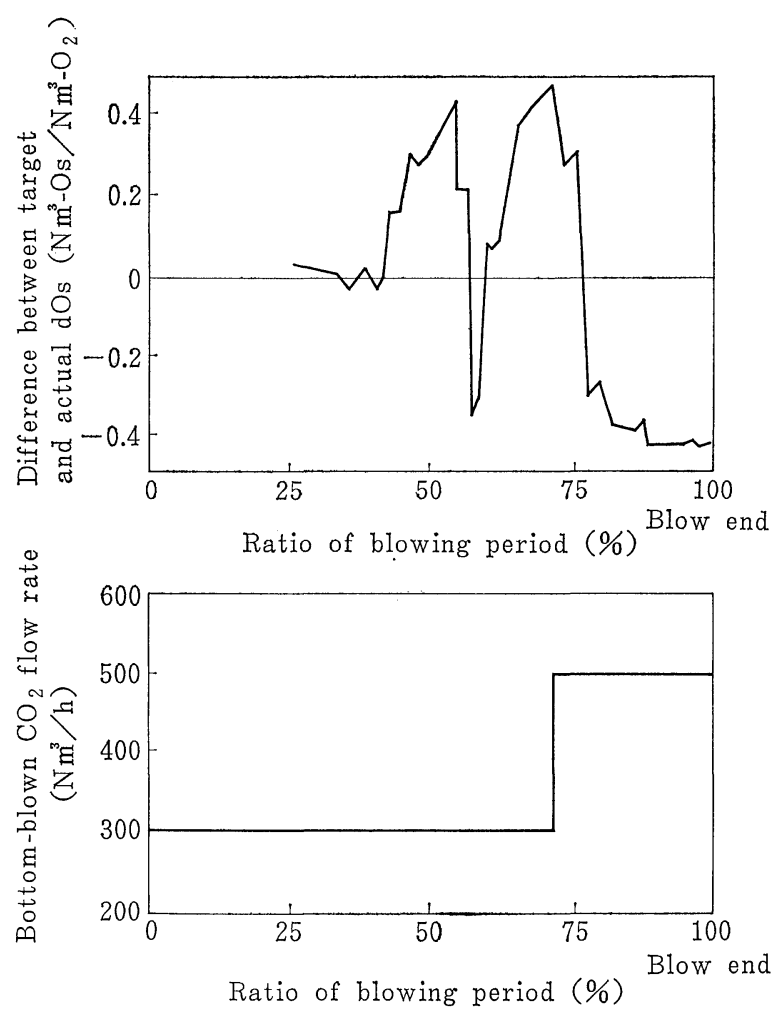

Fig. 11. Bottom-blown $\mathrm{CO}_{2}$ flow rate and difference between target and actual $d \mathrm{Os}$ under program control of bottom-blown gas.
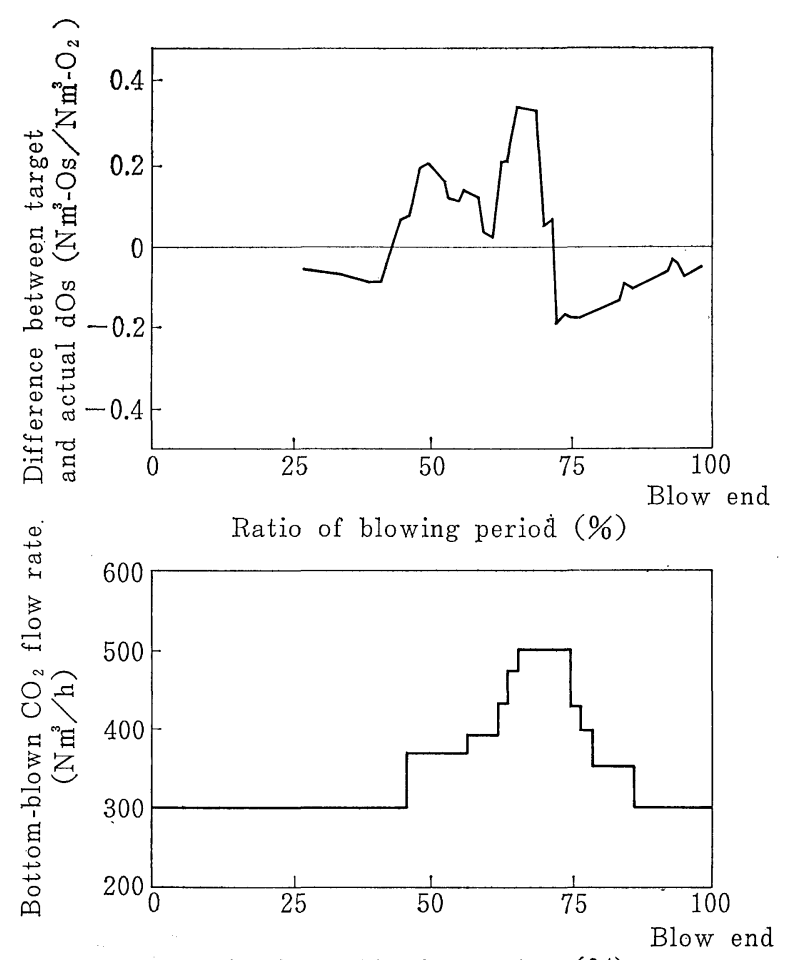

Ratio of blowing period (\%)

Fig. 12. Bottom-blown $\mathrm{CO}_{2}$ flow rate and difference between target and actual $d \mathrm{O}$ s under dynamic control of bottom-blown $\mathrm{CO}_{2}$. 


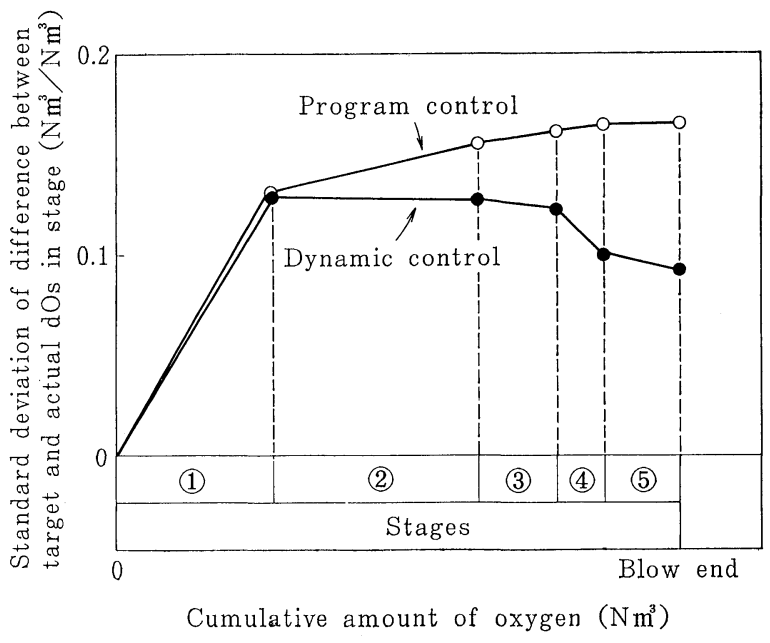

Fig. 13. Comparison of standard deviation of difference between target and actual $d \mathrm{Os}$ by stage under program control/dynamic control of bottom-blown $\mathrm{CO}_{2}$ flow rate.

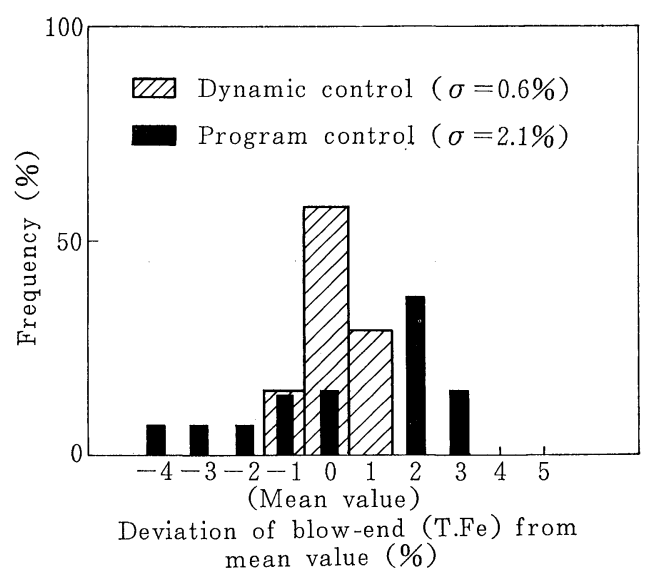

Fig. 14. Comparison of variance of blow-end (T.Fe) under program control/dynamic control of bottom-blown $\mathrm{CO}_{2}$ flow rate.

validity of application of the dynamic optimum control.

So far, it was found the validity of the above control with reference to the behavior of dynamic parameter Os indicating the change in oxidation/reduction condition in the converter. Below, the authors will describe the contributions of the above control system for the improvement of metallurgical characteristics in actual converter blowing operation.

Figure 14 shows the effect of the above control system on (T.Fe) in slag determined by the analysis of slag at the end of blowing, a typical indicator for approximate condition of oxidation potential of convert slag.

Figure 15 shows a comparison of phosphorus concentration of molten steel at the end of blowing, and Fig. 16 shows a comparison of manganese concentration of molten steel at the end of blowing.

In each case, the variance is improved significantly by the application of the above control system. All this is considered ascribable to the dynamic blowing reaction control with the flow rate of bottom-blown

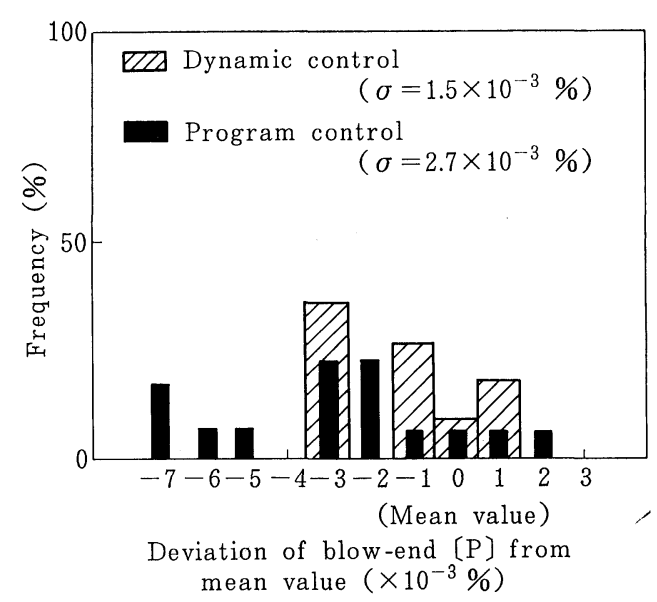

Fig. 15. Comparison of variance of blow-end [P] under program control/dynamic control of bottom-blown $\mathrm{CO}_{2}$ flow rate.

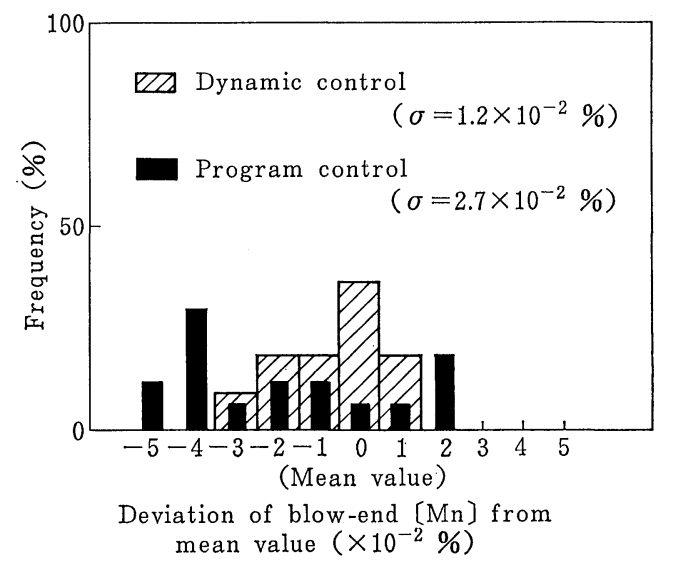

Fig. 16. Comparison of variance of blow-end [Mn] under program control/dynamic control of bottom-blown $\mathrm{CO}_{2}$ flow rate.

$\mathrm{CO}_{2}$ as a manipulated variable, which appreciably improves the controllability of slag/metal reactions during blowing in a top- and bottom-blowing converter, as well as the stability of blowing operation.

\section{Conclusion}

On the basis of information about exhaust gas, the authors calculated the amount of accumulated oxygen (Os) in a top- and bottom-blowing converter which represents the change in condition of oxidation/reduction between hot metal and slag.

Then, the authors studied the effects of gas bottomblowing on the refining characteristics in comparison with those of top-blowing conditions. The findings are summarized below.

(1) By manipulation of the top- and bottom-blowing conditions during blowing operation, it is possible to control the change in oxygen balance of the converter $(d \mathrm{Os})$. The parameter $d \mathrm{Os}$ has a positive correlation with the lance height, and a negative correlation with the flow rates of top-blown oxygen and bottom-blown gas. Thus, by the use of $d \mathrm{Os}$, it is possible to express quantitatively the relationships between hard blow and soft blow by manipulation of the top-blowing lance and between strong agitation and 
weak agitation by bottom-blown gas.

(2) By the manipulation of the flow rate of bottom-blown gas, it is possible to control the blowing reaction stably on the basis of the change in condition of agitation in the converter. The manipulation of the flow rate of bottom-blown gas has a much larger control gain for the variation of $d \mathrm{Os}$ than the manipulation of top-blowing conditions. From this, the manipulation of the flow rate of bottom-blown gas can be evaluated as an effective means to control the blowing reaction.

The authors also made the dynamic control of blowing reactions in a top- and bottom-blowing converter, with the flow rate of bottom-blown gas as a manipulated variable. The findings are summarized below.

(1) Blowing reactions were subjected to the dynamic control by the application of the multistep optimum control theory to a blowing reaction model, with the flow rate of bottom-blown gas as a manipulated variable and the variation of Os as a controlled variable. As a result, the accuracy of Os control during blowing operation improved appreciably.

(2) The dynamic control of the blowing reactions with the flow rate of bottom-blown gas as a manipulated variable improved the stability of blowing operation and the metallurgical characteristics, i.e., the ranges of variances of (T.Fe) in slag, phosphorus and manganese concentrations of molten steel were narrowed appreciably at the blow end.

\section{REFERENGES}

1) K. Mori and M. Sano: Tetsu-to-Hagané, 67 (1981), 672.

2) T. Saito, K. Nakanishi, Y. Kato, T. Nozaki and T. Emi: Tetsu-to-Hagané, 68 (1982), A4.

3) T. Kai, K. Okohira, M. Hirai, S. Murakami and N. Sato: Tetsu-to-Hagané, 68 (1982), A41.

4) M. Kawana, K. Nakanishi, A. Okazaki, J. Nagai, F. Sudo and H. Bada: Tetsu-to-Hagané, 64 (1978), S166.

5) H. Iso, Y. Jyono, M. Honda, K. Arima, M. Kanemoto and Y. Ueda: Tetsu-to-Hagané, 69 (1983), S1012; Trans. Iron Steel Inst., 24 (1984), B173.

6) H. Nakamura, T. Saito, T. Nozaki, K. Suzuki, T. Ohnuma and T. Emi: Tetsu-to-Hagané, 67 (1981), S873.

7) K. Nakanishi, T. Nozaki, R. Uchimura, T. Ohta, M. Saigusa and F. Sudo: Kawasaki Steel Tech. Rep., No. 1 Sep., (1980), 1.

8) H. Iso, Y. Jyono, M. Kanemoto, Y. Ueda, T. Yoshida and K. Isogami: Trans. Iron Steel Inst. Jpn., 27 (1987), 351.

9) Iron and Steel Handbook, II: Manufacturing of Pig Iron and Steel, 3rd Ed., ISIJ, ed., Maruzen, Tokyo, (1979), 496.

10) K. Segawa: Tetsu-Yakin-Hannou-Kougaku, Nikkan Kogyo Shinbunsha, Tokyo, (1969), 118.

11) T. Kai: Doctoral thesis to Kyushu University, (1983).

12) I. D. Landou and M. Tomizuka: Theory \& Practice of Adaptive Control Systems, Ohm-sha, Tokyo, (1981), 55.

13) I. D. Landou: "A Survey of Model Reference Adaptive Techniques, Theory and Applications," Automatica, 10 (1974), 353.

14) I. D. Landou and M. Tomizuka: Theory \& Practice of Adaptive Control Systems, Ohm-sha, Tokyo, (1981), 62.

15) S. Tuji: Saiteki-Seigyo-Gairon, 7th Ed., Yohkendou, Tokyo, (1967).

16) L. T. Fan: The Continuous Maximum Principle, John Wiley \& Sons, New York, (1964). 